\title{
Cerebral autosomal dominant arteriopathy with subcortical infarcts and leukoencephalopathy: a clinicopathological and genetic study of a Swiss family
}

H H Jung, C Bassetti, E Tournier-Lasserve, K Vahedi, M Arnaboldi, V Blatter Arifi, J-M Burgunder

\begin{abstract}
This paper reports a Swiss family affected by a cerebral autosomal dominant arteriopathy with subcortical infarcts and leukoencephalopathy (CADASIL) linked to chromosome 19q12. In three generations several members of this family had recurrent strokelike episodes and, some developed subcortical dementia, migraine-like headaches, and depression. The clinically affected family members had multiple subcortical infarcts and diffuse leukoencephalopathy on MRI. Necropsy of one patient showed a distinctive non-amyloid and non-atherosclerotic angiopathy of small cerebral and leptomeningeal arteries with concentric depositions of a basophilic granular material replacing the smooth muscle cells of the media. Linkage analysis with five chromosome 19 markers spanning the estimated CADASIL interval showed the absence of any recombinant and positive Lod scores, highly suggestive of linkage of this condition to the CADASIL locus. CADASIL might be an underestimated cause of familial stroke and should be considered in the differential diagnosis of hereditary stroke.
\end{abstract}

(F Neurol Neurosurg Psychiatry 1995;59:138-143)

Department of

Neurology, University

Hospital Bern, Bern,

Switzerland

$\mathrm{H}$ H Jung

C Bassetti

V Blatter Arifi

$\mathrm{J}-\mathrm{M}$ Burgunder

Faculté de Médecine

Necker-Enfants

Malades, Inserm U25,

Paris, France

E Tournier-Lasserve

K Vahedi

Department of

Pathology, University

Hospital Zürich,

Zürich, Switzerland

M Arnaboldi

Correspondence to:

Dr C Bassetti, Department

of Neurology, University

Hospital Bern, CH-3010

Bern, Switzerland.

Received 3 January 1995

and in final revised form

7 April 1995

Accepted 12 April 1995 disorder with subcortical ischaemic strokes and leukoencephalopathy, ${ }^{89}$ and more recently, cerebral autosomal dominant arteriopathy with subcortical infarcts and leukoencephalopathy (CADASIL). ${ }^{1011}$ All these disorders share similar clinical features, pathological findings, and neuroradiological changes. Recently, the disease locus in two unrelated French families has been ascribed to chromosome $19 \mathrm{q} 12$ by genetic linkage analysis. ${ }^{12}$

In this paper we describe a Swiss family affected by autosomal dominant disease characterised by recurrent stroke-like episodes and the development of subcortical dementia showing the same genetic linkage to chromosome 19.

\section{Patients and methods}

Twelve members belonging to two generations of a family originating from the eastern part of Switzerland were examined. Eight of them were females and four were males. Four were aged between 13 and 19 and eight between 31 and 40. All members gave informed consent to the examinations. Clinical and paraclinical data available from medical records of deceased members of the family were also reviewed. Figure 1 shows the pedigree of family members aged over 30 . Table 1 summarises the clinical and radiological findings of the affected family members. Cerebral MRI was carried out in 10 of the 12 examined members (General Electric Signa, 1.5 Tesla, $\mathrm{T} 1$ and $\mathrm{T} 2$ weighted transversal and sagittal sections). Brain MRI was not done in two members because of claustrophobia. All those examined had standard laboratory investigations (red and white blood cell counts, erythrocyte sedimentation rate, protein electrophoresis, activated partial thromboplastin time and prothrombin time tests, serum electrolytes, renal and liver function tests, glycaemia, cholesterol, tryglycerides), determination of several antibodies (antinuclear antibodies and antibodies directed against double and single strand DNA, mitochondria, SS-A, SS-B, c-ANCA, and pANCA, cardiolipin/phospholipid), and screening for lipids, mucopolysaccharides, and arylsulphatase $\mathrm{A}$ in the urine. The index patient underwent further examination as described next. 

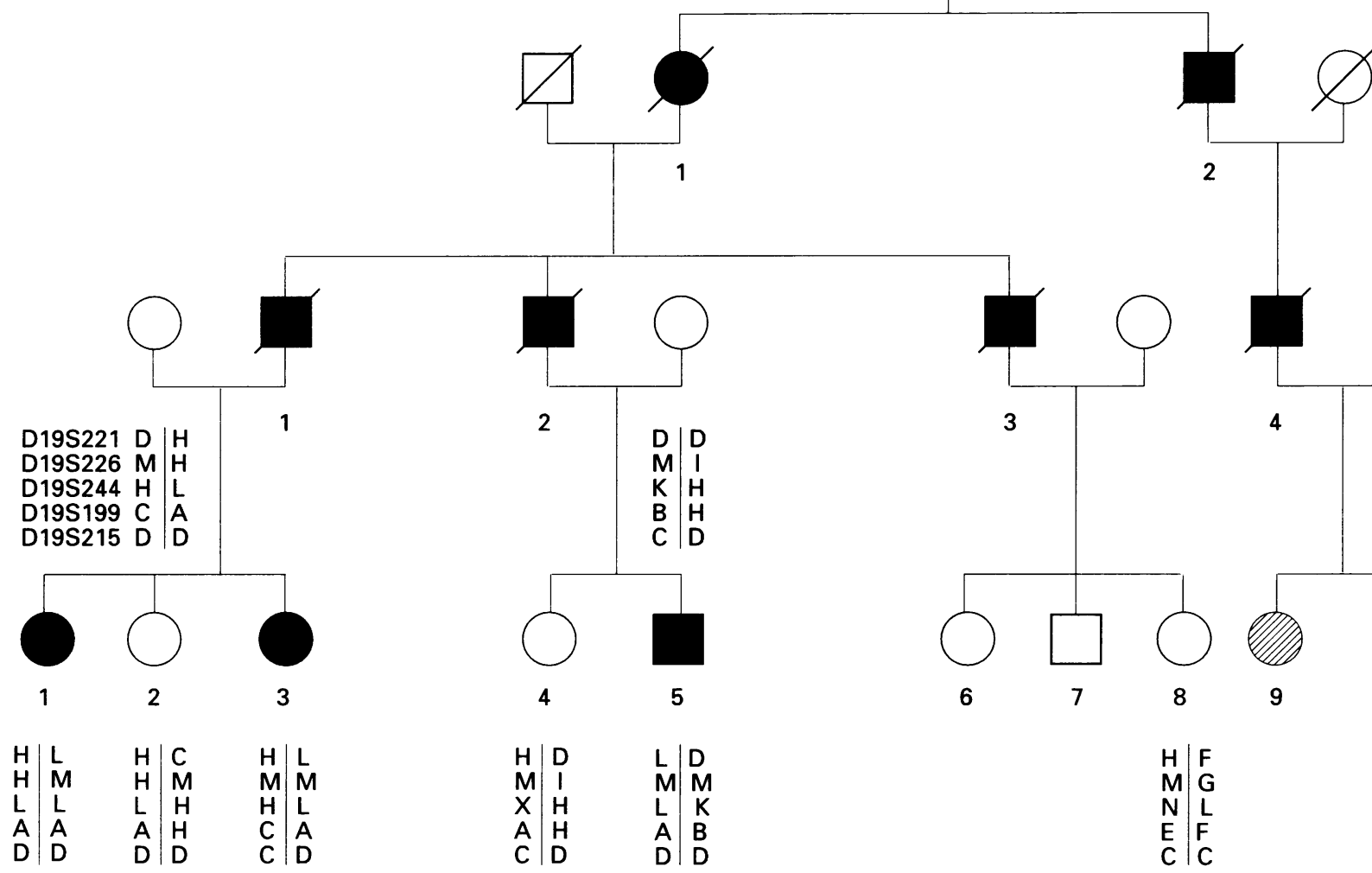

6

8

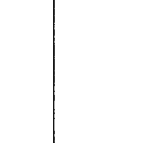

IV

Figure 1 Pedigree of the family over four generations (filled symbols represent affected patients, empty symbols non-affected subjects, and hatched symbols subjects not examined). Markers spanning the interval containing the CADASIL gene are indicated below the examined informative members due to their estimated position on the short arm of chromosome 19

INDEX PATIENT (IV 5)

The patient was referred to our service with possible multiple sclerosis. At the age of 38 he had suddenly developed a right sided facial palsy that recovered with only minor residual symptoms. Two years later he experienced acute paraesthesia and dysaesthesia of the left side. The first clinical examination showed a residual right sided facial palsy, hyperpathy of the left side, slight hypaesthesia on the left hand, and a depressive mood with crying spells. Neuropsychological testing showed mild amnesia and concentration and attentional deficits. There was no history of headache and major cardiovascular risk factors were absent.

Table 1 Clinical and radiological features of seven patients in generations II to IV

\begin{tabular}{|c|c|c|}
\hline $\begin{array}{l}\text { Patients } \\
\text { (onset age) }\end{array}$ & Clinical features & Radiological features \\
\hline II 1 (45) & $\begin{array}{l}\text { Recurrent stroke-like episodes, progressive subcortical } \\
\text { dementia }\end{array}$ & No radiological examination performed \\
\hline III $1(40)$ & $\begin{array}{l}\text { Migraine accompagnée. At age } 50 \text { progressive subcortical } \\
\text { dementia. At } 55 \text { recurrent stroke-like episodes }\end{array}$ & $\begin{array}{l}\text { CT: multiple bilateral hypodensities in } \\
\text { the white ganglia, leukoaraiosis }\end{array}$ \\
\hline III $2(53)$ & $\begin{array}{l}\text { Transient stroke-like episode. At age } 59 \text { progressive } \\
\text { subcortical dementia. At } 62 \text { stroke-like episode with } \\
\text { persistent right sided hemiplegia. Death at } 63\end{array}$ & $\begin{array}{l}\text { CT: multiple bilateral hypodensities in } \\
\text { the white matter and in the basal } \\
\text { ganglia, leukoaraiosis }\end{array}$ \\
\hline III $4(40)$ & $\begin{array}{l}\text { Episodes of major depression. At age } 52 \text { first transient } \\
\text { stroke-like episode. At } 54 \text { multiple stroke-like episodes } \\
\text { and progressive subcortical dementia. Death at } 60\end{array}$ & $\begin{array}{l}\text { CT: multiple bilateral hypodensities in } \\
\text { the white matter and in the basal } \\
\text { ganglia, leukoaraiosis }\end{array}$ \\
\hline IV 1 (33) & $\begin{array}{l}\text { Migraine-like headaches. Two episodes of migraine } \\
\text { accompagnée. One transient stroke-like episode. } \\
\text { No neurological deficits }\end{array}$ & $\begin{array}{l}\text { MRI: multiple bilateral lesions in the } \\
\text { white matter and basal ganglia; } \\
\text { leukoencephalopathy }\end{array}$ \\
\hline IV 3 (35) & $\begin{array}{l}\text { Recurrent attacks of migraine since youth. At } 35 \text { migraine } \\
\text { accompagnée. At } 37 \text { first transient stroke-like episode. } \\
\text { No neurological deficits }\end{array}$ & $\begin{array}{l}\text { MRI: multiple bilateral lesions in the } \\
\text { white matter and basal ganglia, } \\
\text { thalamus and centrum semiovale; } \\
\text { leukoencephalopathy }\end{array}$ \\
\hline IV $5(38)$ & $\begin{array}{l}\text { Several stroke-like episodes. Clinically left sided } \\
\text { hyposensibility, motor aphasia and apraxia of the } \\
\text { right hand. Mild neuropsychological deficits }\end{array}$ & $\begin{array}{l}\text { MRI: multiple bilateral lesions in the } \\
\text { white matter, basal ganglia corpus } \\
\text { callosum, and right thalamus; } \\
\text { leukoencephalopathy }\end{array}$ \\
\hline
\end{tabular}


T1 weighted brain MRI showed multiple well delineated lesions in the white matter, corona radiata, and centrum semiovale as well as in the basal ganglia and right thalamus. There was also one lesion in the corpus callosum. T2 weighted brain MRI showed confluent white matter hyperintensities. Laboratory examination as mentioned yielded normal results. Coagulation variables (thrombocytes, protein $\mathrm{C}$ and $\mathrm{S}$, thrombin time test, fibrinogen, factors II, V, VII, and X, and fibrin/fibrinogen degradation products), serum lactate, and subanaerobic threshold exercise test (SATE test) were within the normal range. Examination of CSF gave normal results for cell count, protein, and glucose; CSF immunoglobulins were normal by isoelectric focusing. Duplex and Doppler sonographic

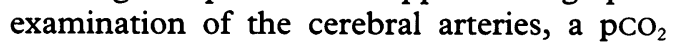
reactivity test, four vessel cerebral angiography, chest radiographs, ECG, transoesophageal echocardiography, and visual and motor evoked potentials were normal. Somatosensory evoked potentials showed a low amplitude of early cortical responses on the right side due to the thalamic lesion. Biopsy of the quadriceps muscle showed a slightly augmented intracellular lipid accumulation of unknown origin. Biopsy of the sural nerve showed slight axonal and demyelinating damage without alterations of endoneural and perineural vessels at light microscopy. A trial prophylactic treatment with aspirin was started. Six months later another stroke-like episode occurred with symptoms of motor aphasia and ideomotor apraxia. There was worsening of the right sided facial paresis with newly developed complete left sided hemihypaesthesia.

\section{PATIENT IV 1}

This woman reported a history of allergic asthmoid reaction, rhinitis, and urticaria. At the age of 33 she experienced for the first time several attacks of severe migraine-like

Figure 2 Brain MRI of patient IV 1;T2 weighted MRI showing multiple, well delineated lesions of the white matter predominantly adjacent to the ventricles and in the basal ganglia, and extended confluent white matter lesions headaches in the left hemicranium with nausea, photophobia, and phonophobia. Two episodes of 10 minutes duration were accompanied by paraesthesia and hypaesthesia of the left arm and face without motor symptoms. One short episode of sudden paraesthesia of the left hand without headaches was also reported. Clinical and laboratory examinations were normal. Brain MRI showed multiple, well delineated lesions in T1 weighted images in the white matter and basal ganglia. T2 weighted images showed confluent white matter lesions (fig 2).

RECORDS OF DECEASED FAMILY MEMBERS A history of stroke-like episodes was documented in four deceased members in generation II and III in the absence of major cardiovascular risk factors (table 1). The mean age of onset was 51 . In addition, all patients developed symptoms of subcortical dementia with a documented mean age of onset of 55. One of the deceased patients (III 1) showed symptoms of hemiplegic migraine in his $40 \mathrm{~s}$. Another patient was admitted to hospital several times due to major depression between his third to sixth decade. In three of the deceased affected members (III 1, III 2, and III 4) brain CT was available. These showed multiple small circumscribed hypodensities without contrast enhancement localised predominantly in the basal ganglia and the adjacent white matter together with diffuse low densities in the white matter.

\section{HISTOPATHOLOGICAL EXAMINATION}

Necropsy had been performed on one family member (III 2, aged 59) after his death in 1986. His brain weighed $1360 \mathrm{~g}$. Macroscopic examination showed multiple ischaemic lesions of the cerebral cortex in the left temporo-occipital region and the right cerebellum. The basal ganglia and the adjacent white matter showed multiple small cystic lesions. Only a minor stenosing atherosclerosis of the basal cerebral arteries was found.

Archived paraffin embedded brain tissue was used to prepare new slices, which were stained with haematoxylin-eosin, elastica van Gieson, congo red, and thioflavine. Selected areas were examined immunohistochemically with monoclonal antibodies directed against smooth muscle actin.

Histologically, the main abnormalities were found in small arteries up to a diameter of 2 $\mathrm{mm}$, in some meningeal arteries, in most of the vessels of the basal ganglia and thalamus, and in practically all vessels of the white matter. There were few arterial changes in the cortex of the cerebrum and the cerebellum. The abnormalities consisted of concentric depositions of granular material in a slightly thickened media. The granules were basophilic, replaced the smooth muscle cells, and were found in widely varying amounts (fig 3 ). The loss of smooth muscle cells was confirmed by the immunohistochemical examination with a monoclonal antibody directed against smooth muscle actin (fig 4). Some cerebral arteries also showed a loss of their 


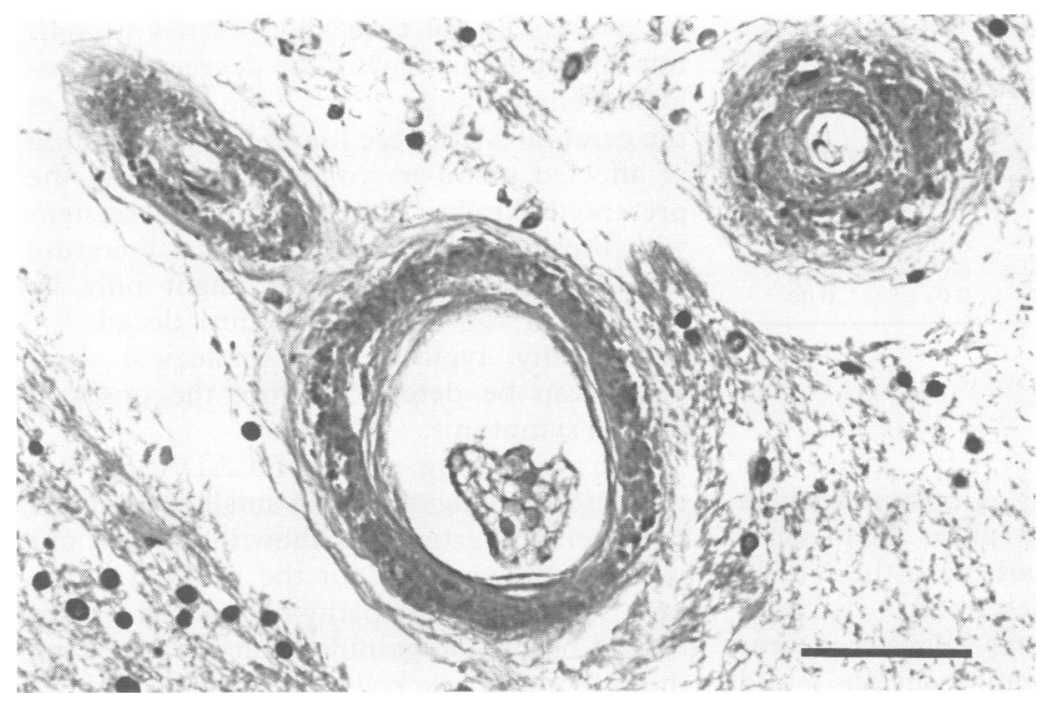

Figure 3 Granular degeneration of the media and splitting of the lamina elastica interna in small arteries of the white matter. Depositions of granules of basophilic aspect (haematoxylin and eosin; bar represents $50 \mu \mathrm{m}$ ).

normal texture and a splitting of the lamina elastica interna, in rare cases accompanied by a diffuse hyalinosis of the media. There were no typical signs of a long lasting arterial hypertension or signs of vasculitis. Fluorescence after thioflavine staining and congo red were negative for amyloid depositions. Arteries with occlusions or thrombosis could not be detected. There were no abnormalities of venous vessels.

In general the brain tissue showed multiple, partially cystic transformed infarcts, lying predominantly in the white matter and the basal ganglia often with centrally located altered vessels. There was a diffuse loss of ganglion cells in the adjacent tissue with a mild lymphocytic infiltration, iron pigment deposition in macrophages, and a pronounced astrocytic gliosis.

\section{LINKAGE ANALYSIS}

Genetic linkage analysis was conducted as described. ${ }^{12}$ Briefly, all clinically symptomatic patients with the typical alterations on brain MRI were considered as affected. Asymptomatic subjects with normal cerebral MRI were considered as having an unknown status when aged below 35 . Six were fully informative. Three of them (IV1, IV3, and IV5) were considered as affected and three of them (IV2, IV4, and IV8) as healthy. Those belonging to generation $\mathrm{V}$ were considered as non-informative and were not analysed. DNA was extracted from peripheral blood lymphocytes of all potentially informative subjects. Five chromosome 19 markers were selected for their informativity-namely, D19S221, D19S226, D19S244, D19S199, and D19S215. ${ }^{1314}$ The examined markers have previously been shown to span a $14 \mathrm{cM}$ interval containing the CADASIL locus. ${ }^{12}$ They are drawn on fig 1 according to their estimated position on the short arm of chromosome 19. D19S244 is located at $\Theta=0$ from D19S226 and D19S199 is centromeric to D19S226 and located at $\Theta=2 \mathrm{cM}$ from D19S226 (Weissenbach et $a l^{14}$ and J Weber,

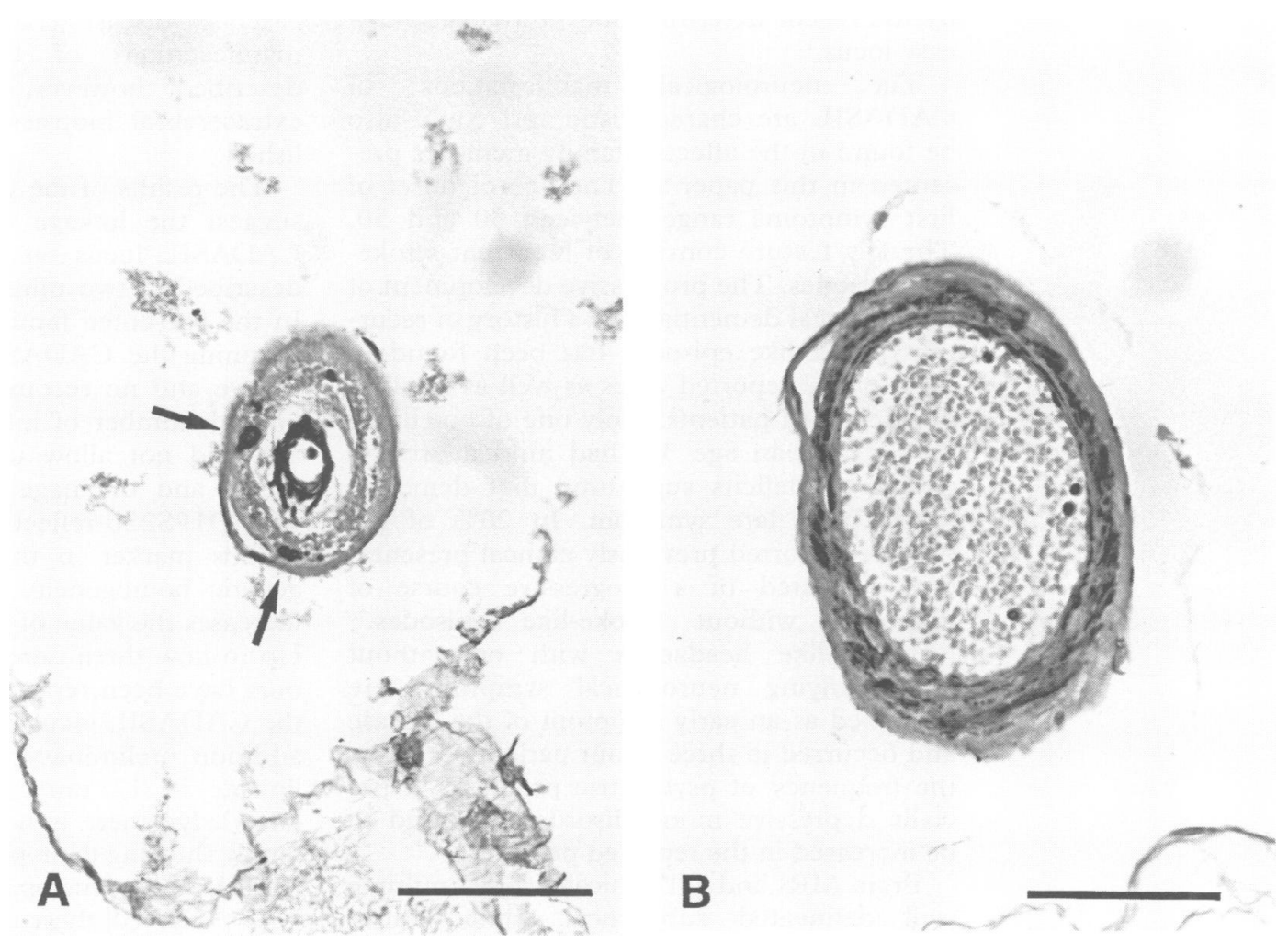

Figure 4 Immunhistochemical examination of smooth muscle actin in the media using a monoclonal antibody (arrow). Figure 4 Immunhistochemical examination of smooth muscle actin in the media using a monoclonal antibody (arrow).
$(A)$ granular degeneration of the media with nearly total loss of smooth muscle cell actin; (B) normal amount of smooth muscle cell actin in a patient with vascular encephalopathy associated with hypertension (haematoxylin and eosin; bars represent $100 \mu \mathrm{m}$ ) 
Table 2 Lod scores obtained for various values of recombination fractions ( $\Theta$ ) of five markers spanning the CADASIL interval

\begin{tabular}{|c|c|c|c|c|c|c|}
\hline \multirow[b]{2}{*}{ Marker } & \multicolumn{6}{|l|}{$\Theta$} \\
\hline & 0 & $0 \cdot 1$ & $0 \cdot 2$ & $0 \cdot 3$ & 0.4 & 0.5 \\
\hline $\begin{array}{l}\text { D19S221 } \\
\text { D19S226 } \\
\text { D19S244 } \\
\text { D19S199 } \\
\text { D19S215 }\end{array}$ & $\begin{array}{r}1 \cdot 71 \\
-0.06 \\
0.85 \\
1.12 \\
0.46\end{array}$ & $\begin{array}{r}1.36 \\
-0.04 \\
0.73 \\
0.89 \\
0.32\end{array}$ & $\begin{array}{r}0.97 \\
-0.02 \\
0.55 \\
0.62 \\
0.19\end{array}$ & $\begin{array}{r}0.56 \\
-0.01 \\
0.33 \\
0.33 \\
0.08\end{array}$ & $\begin{array}{c}0.17 \\
-0.003 \\
0.10 \\
0.09 \\
0.01\end{array}$ & $\begin{array}{l}0.00 \\
0.00 \\
0.00 \\
0.00 \\
0.00\end{array}$ \\
\hline
\end{tabular}

personal communication). Linkage analysis was conducted with the allele frequencies found for the selected markers in the CEPH families as previously described. ${ }^{12}$ Table 2 shows Lod scores for various values of recombination fractions. No recombinant was found with any of the markers (fig 1). These combined data strongly suggest the linkage of the disorder present in this family with the CADASIL locus.

\section{Discussion}

The diagnosis of an autosomal dominant arteriopathy with stroke-like episodes and leukoencephalopathy (CADASIL) in the family presented here is established by the typical clinical courses, the neuroradiological findings, the arteriopathic alterations, and the results of the genetic linkage analysis that strongly suggests the disease locus on chromosome 19. Similar syndromes have been characterised clinically in several reports during the past two decades. ${ }^{4-11}$ The characterisation of a genetic entity has been made possible by the recent determination of a genetic disease locus. ${ }^{12}$

The neurological manifestations of CADASIL are characteristic and could also be found in the affected family members presented in this paper. ${ }^{4-11}$ The age of onset of first symptoms ranges between 30 and 50 . The key feature consists of recurrent strokelike episodes. The progressive development of a subcortical dementia after a history of recurrent stroke-like episodes has been found in most of the reported cases as well as in all of our deceased patients. Only one of our living patients (mean age 38 ) had mild neuropsychological deficits suggesting that dementia might be a late symptom. In $20 \%$ of the patients reported previously clinical presentation consisted of a progressive course of dementia without stroke-like episodes. ${ }^{10}$ Migraine-like headaches with or without accompanying neurological symptoms are described as an early symptom of the disease and occurred in three of our patients. Finally, the frequency of psychiatric problems, especially depressive mood disorders, seemed to be increased in the reported patients.

Brain MRI and CT typically show multiple well delineated subcortical white matter lesions and diffuse leukoencephalopathy. Lesions can also be found in the basal ganglia, thalamus, corpus callosum, and infratentorial brain structures. Neuroradiological changes are present in all clinically affected persons but do not correlate with the degree of neurological impairment. ${ }^{6-10} 1215-17$ No alterations in the cerebral MRI were found in two offspring of affected members younger than 20 in the presented family. This finding is consistent with those reported in the medical literature that carriers of the disease might only be detected at the end of the third decade. ${ }^{1012}$ Noteworthy, typical neuroradiological alterations can be detected before the onset of clinical symptoms.

The underlying cause of CADASIL is a characteristic angiopathy of small and middle sized cerebral arteries as shown in one of our patients and reported in the medical literature. ${ }^{41116}$ This angiopathy consists of deposition of basophilic granular material replacing the smooth muscle cells of the media without appreciable atherosclerotic alterations or amyloid depositions. The angiopathic alterations are predominantly localised in the white matter but to a lesser extent they are also found in the basal ganglia, thalamus, leptomeninges, and cortical cerebral and cerebellar arteries. Our immunohistochemistry results show that the depositions replace or destroy the smooth muscle cells of the media in affected cerebral vessels. Due to the lack of necropsy material we were not able to perform histopathological examinations of extracerebral organs. Nerve and muscle biopsy of our index patient showed only non-specific findings at light microscopy. Nevertheless, some specific alterations have been described in vessels of the spinal cord, ${ }^{416}$ myocardium, ${ }^{11}$ and more recently, skin and muscle ${ }^{18}$ suggesting the possibility that CADASIL is a more generalised vascular disease. No extracerebral clinical manifestations of CADASIL have been described, however, and the reliability of extracerebral biopsies remains to be established.

The results of the genetic analysis strongly suggest the linkage of the disorder to the CADASIL locus on chromosome $19 \mathrm{q} 12$ as described in two unrelated French families. ${ }^{12}$ In the presented family, most of the markers spanning the CADASIL interval were informative and no recombinant was found. The limited number of informative meiosis available did not allow us to obtain higher lod scores and the negative lod score obtained with D19S226 reflects the poor informativity of this marker in this family. In turn, the genetic homogeneity of CADASIL strongly increases the value of the obtained lod scores. Up to now three unrelated families including ours have been reported to show a linkage to the CADASIL locus on chromosome 19q. In addition preliminary data showed a positive linkage in 12 unrelated families. ${ }^{19}$ To our knowledge there is no report of an unlinked family showing the typical clinical, neuroradiological, and histopathological pattern of CADASIL. All these data form increasing evidence that CADASIL is a genetically homogenous disorder and might be more widespread than presently thought.

Several diseases have been previously 
mapped on chromosome 19. Among them, familial hemiplegic migraine is linked to the same locus as CADASIL. 2021 The fact that many patients with CADASIL report a history of migraine-like episodes suggests similarities in the pathogenesis of the two conditions. The late onset form of Alzheimer's disease has also been mapped on chromosome 19. Histopathological features of CADASIL in association with amyloid plaques and neurofibrillary tangles, however, have been reported in only one patient. ${ }^{17}$ Furthermore, recurrent strokes rarely accompany Alzheimer's disease and dementia in Alzheimer's disease is of a vascular type whereas dementia in CADASIL is of a subcortical type. ${ }^{22}$ Finally, the closest markers linked to CADASIL and Alzheimer's disease, are at a distance of $15 \mathrm{cM}$, placing the Alzheimer's disease marker outside the interval of the gene probably affected in CADASIL. ${ }^{12}$ Therefore, the association of CADASIL and Alzheimer's disease in the reported patient might be coincidental.

By contrast with the increasing knowledge of the clinical and genetic features, the pathogenesis of CADASIL remains unclear. An immunopathological process has been proposed because of perivascular infiltrates in some cases, ${ }^{17}$ steroid responsive peripheral blood lymphocyte abnormalities, ${ }^{23}$ and dysglobulinaemia in one patient whose condition improved after plasmapheresis. ${ }^{10}$ In one affected family, an association of CADASIL with a hereditary protein $S$ deficiency has been reported. ${ }^{24}$ These conditions have not been found in most reports, including ours, and might therefore be coincidental. Consequently, other than correction of vascular risk factors there is no rational treatment for CADASIL to date. In one of our patients aspirin failed to prevent further stroke-like episodes.

CADASIL turns out to be a syndrome with distinctive clinical, neuroradiological, and histopathological features linked to a specific chromosomal locus in several unrelated families suggesting a genetic homogeneity. The present report supports the increasing evidence that CADASIL is a form of hereditary stroke that is not as rare as previously thought. Brain MRI is probably the most sensitive diagnostic test in the early stages whereas the role of muscle or skin biopsy remains to be established. The pathogenic mechanism leading to the characteristic angiopathy and the reason for the predilection of cerebral vessels remain unknown. Furthermore, the underlying metabolic, immunological, or haematological causes of the disorder remain to be established. The locus assignment represents the first step in determining the defective gene and, hopefully, the identification of a possible gene product. Further research at the molecular level is needed to provide more insight in the understanding of CADASIL and lead to the possibility of therapeutic as well as prophylactic interventions.
We thank Professor L Egloff, Institute of Pathology, Kantonsspital Winterthur, Switzerland, for the necropsy specimens; Dr C Ozdoba, Department of Radiology, University Hospital Bern, Switzerland, for performing MRI; Professor B Lämmle, University Hospital Bern, Department of Haematology, Switzerland, for examining the coagulation variables, and Dr K Rösler, Department of Neurology, University Hospital Bern, Switzerland, for performing the muscle and nerve biopsies.

1 Natowicz M, Kelley R. Mendelian etiologies of stroke. Ann Neurol 1987;22:175-92.

2 Pavlakis SG, Philipps PC, DiMauro S, DeVivo DC, Rowland LP. Mitochondrial myopathy, encephalopathy, lactic acidosis and stroke like episodes: a distinctive clinical syndrome. Ann Neurol 1984;16:481-8.

3 Mudd SH, Levy HL, Skovby F. Disorders of sulfuration. In: Stanbury JB, Wyngaarden JB, Fredrickson DS, eds. The metabolic basis of inherited diseases. New York: McGraw-Hill, 1989:693-734.

4 Stevens DL, Hewlett RH, Brownell B. Chronic familial vascular encephalopathy. Lancet 1977;2:1364-5.

5 Sourander P, Walinder J. Hereditary multi-infarct dementia. Acta Neuropathol (Berl) 1977;39:247-54.

6 Sonninen V, Savontaus ML. Hereditary multi-infarct dementia. Europ Neurol 1987;27:209-15.

7 Davous P, Fallet-Bianco C. Démence sous-corticale familiale avec leucoencéphalopathie arteriopathique: observation clinico-pathologique. Rev Neurol (Paris) 1991;147: 376-84.

8 Mas JL, Dilouya A, deRecondo J. A familial disorder with subcortical ischemic strokes, dementia and leukoencephalopathy. Neurology 1992;42:1015-9.

9 Salvi F, Michelucci R, Plasmati R, Parmeggiani L, Zonari $P$, Mascalchi M, Tassinari CA. Slowly progressive familial dementia with recurrent strokes and white matter hypodensities on CT scan. Ital $\mathcal{f}$ Neurol Sci 1992;13: 135-40.

10 Tournier-Lasserve E, Iba-Zizen M-T, Romero N, Bousser M-G. Autosominal dominant syndrome with stroke like episodes and leukoencephalopathy. Stroke 1991;22: 1297-302.

11 Baudrimont M, Dubas F, Joutel A, Tournier-Lasserve E, Bousser M-G. Autosomal dominant leukoencephalopathy and subcortical ischemic stroke: a clinicopathological study. Stroke 1993;24:122-5.

12 Tournier-Lasserve E, Joutel A, Melki J, Weissenbach J, Lathrop GM, Chabriat $\mathrm{H}$, et al. Cerebral autosominal dominant arteriopathy with subcortical infarcts and leukoencephalopathy maps to chromosome $19 \mathrm{q} 12$. Nature Genetics 1993;3:256-9.

13 Hudson TS, Engelstein M, Lee MK, Ho EC, Robenfield MJ, Adams CP, et al. Isolation and chromosomal assignment of 100 highly informative human simple repeat ment of 100 highly informative human

14 Weissenbach J, Gyapay G, Dib C, Vignal A, Morisette J, Millasseau P, et al. A second generation linkage map of the human genome. Nature 1992;359:794-801.

15 Berthier E, Broussolle E, Garcia-Jacquier M, Tommasi M, Chazot G. Leucoencephalopathie artériopatique juvénile: Etude anatomoclinique d'un cas. Rev Neurol (Paris) 1992;148:146-9.

16 Guitérrez-Molina M, Caminero Rodriguez A, Martinez Garcia C, Arpa Guitérrez J, Morales Bastos C, Amer G. Small arterial granular degeneration in familial Binswanger's syndrome. Acta Neuropathol 1994;87: 98-105.

17 Gray F, Robert F, Labrecque R, Chrétien F, Baudrimont M, Fallet-Bianco C, Mikol J, Vinters HV. Autosomal dominant arteriopathic leuko-encephalopathy and Alzheimer's disease. Neuropathol Appl Neurobiol 1994;20: Alzheim

18 Ruchoux M-M, Chabriat H, Bousser M-G, Baudrimont $M$, Tournier-Lasserve E. Presence of ultrastructural arterial lesions in muscle and skin vessels of patients with CADASIL. Stroke 1994;25:2291-2.

19 Tournier-Lasserve E, Nibbio A, Vahedi K, Chabriat $\mathrm{H}$, Nagy T, Joutel A, et al. Genetic analysis of 12 unrelated CADASIL families: demonstration of genetic homogeneity. Physical mapping of the gene. Am $\mathcal{f}$ Hum Genet 1994;55(suppl):A205.

20 Joutel A, Bousser M-G, Biousse V, Labauge P, Chabriat $\mathrm{H}$, Nibbio $\mathrm{A}$, et al. A gene for familial hemiplegic migraine maps to chromosome 19. Nature Genetics 1993; 5:40-5.

21 Joutel A, Bousser MG, Biousse V, Labauge P, Chabriat $H$, Nibbio A, et al. Migraine hémiplegique familiale. Libbio A, et al. Migraine hémiplegique familiale. Localisation d'un gène responsable sur
19. Rev Neurol (Paris) 1994;150:340-5.

22 Chui HC, Victoroff J, Margolin D, Jagust W, Shankle R, Katzman R. Criteria for the diagnosis of ischemic vascular dementia proposed by the state of California Alzheimer's disease diagnostic and treatment centers. Neurology 1992;42:473-80.

23 Behan PO, Kennedy PGE. Chronic familial cerebral vasculopathy with peripheral blood lymphocyte abnormalities. Ann Neurol 1981;10:74.

24 Güntert D, Hungerbühler H, Hess K. Familiäres Syndrom mit rezidivierenden Insulten und dementieller Entwicklung mit subcortikaler mikroangiopathischer Leukoencephalopathie, assoziiert mit ebenfalls familiärem Protein-S-Mangel [abstract]. Deutscher Neurologenkongress 1994;PD69. 